\title{
Türkiye'de bisiklet Cycling in Turkey: Reasons kullanımı: Bisiklet kullanma and benefits of cycling nedenleri ve elde edilen faydalar
}

\author{
Funda Koçak ${ }^{1}$
}

\begin{abstract}
The purpose of this research is to reveal of cyclist, reasons and benefits of using bicycle. In this regard, 110 female (Mage $=30.46, \mathrm{SD}=$ 8.78) and 496 male (Myaş= 30.47; $\mathrm{SD}=10.12$ ), who were totally 606 cyclist selected by using convenience sampling sampling method, participated in the research voluntarily. In order to determine the reasons and benefits of cycling, personal information form and a threesection-questionnaire, which was prepared by the researcher were used in the research. In the data analysis, frequency, percentage, mean, standard deviation, X2-Chi Square and Cronbach's Alpha internal consistency coefficient tests were used. Participants have stated the reasons as traveling, having interest in cycling, and staying healthy, and they have stated the benefits as feeling healthier, stronger, happier, and overcoming daily stress. As a result, the higher the income and education level get, the less people participate cycling. Also, it has been observed that single people have more positive attitude towards cycling compared to married people. In addition to this, gender, working status and duration have no effect on individuals' participate cycling.
\end{abstract}

Keywords: Bicycle; cyclist; benefit; reasons for participate.

(Extended English abstract is at the end of this document)

\section{Özet}

$\mathrm{Bu}$ araştırmanın amacı; Türkiye'deki bisiklet kullanıcilarının bisiklet kullanma nedenlerini ve bisiklet kullanımının sağladığı faydaları ortaya koyabilmektir. Bu amaçla kolayda örnekleme yöntemi kullanılarak seçilen 110 kadın (Myas= $30.46, \mathrm{SD}=8.78)$ ve 496 erkek $(\mathrm{M} y a s=30.47$; $\mathrm{SD}=10.12$ ) olmak üzere 606 bisiklet kullanıcisı araştırmaya gönüllü olarak katılmıştır. Araştırmada kişisel bilgi formu, katılımcıları bisiklet kullanma nedenleri ve katılımciların bisiklet kullanımı sonucunda elde ettikleri faydaları ortaya koymak amaciyla araştırmac1 tarafindan hazırlanmış üç bölümden oluşan anket kullanılmıştır. Verilerin analizinde frekans, yüzde, ortalama, standart sapma, KiKare (X2-Chi Square) ve Cronbach's Alpha iç tutarlik katsayısı testlerinden yararlanılmıştır. Katilimcilar bisiklet kullanma nedenlerini, gezmek, bisiklet sporunu sevmek ve sağlı̆̆1 korumak olarak belirtirken, elde ettikleri faydaları ise daha sağlıklı ve güçlü hissetmek, daha mutlu hissetmek ve günün stresini atmak olarak belirtmişlerdir. Sonuç olarak gelir düzeyi ve eğitim düzeyinin artması bisiklet kullanımına yönelik olumlu görüşleri azaltırken, bekarların görüşlerinin evlilere göre daha olumlu olduğu görülmüştür. Bununla birlikte cinsiyet, çalışma durumu ve bisiklet kullanma süresi bireylerin bisiklet kullanımını etkilememektedir.

Anahtar Kelimeler: Bisiklet; bisiklet kullanıcısı; fayda; kullanım nedeni.

\footnotetext{
${ }^{1}$ Assist. Prof., Ankara University, Faculty of Sport Sciences, Department of Sports Management, fkocak@ankara.edu.tr
} 
Koçak, F. (2016). Türkiye'de bisiklet kullanımı: Bisiklet kullanma nedenleri ve elde edilen faydalar. Journal of Human Sciences, 13(3), 5760-5771. doi:10.14687/ihs.v13i3.4190

\section{Giriş}

Günümüzde bisiklet kullanımının pek çok nedeni vardır. Bisiklet kullanımının tur, yarış, dağ, rekreasyonel, kamu hizmeti, işe gidip gelme (commute biking) amaçlı pek çok farklı türü bulunmaktadır (Daley \& Rissel, 2011). Bu türlerin hepsinin kendisine özgü bazı özellikleri bulunmaktadır (Horton et al., 2007). Ardahan ve Mert (2014b) bisiklet kullanımını açık alan etkinliği olarak ele alarak, rekabet şansının bulunduğu hem profesyonel hem de sportif amaçlı, rekreasyonel ya da ulaşıma yönelik bir spor olarak tanımlamışlardır.

Düzenli bisiklet kullanımı daha az kirlilik ve trafik sıkışıklığı sağlarken, bireyin sağlığını ve iyilik durumunu geliştirici etkiye sahiptir (Daley \& Rissel, 2011). İşe giderken ulaşım aracı olarak bisiklet kullanmanın hem kadınlarda hem de erkeklerde fiziksel performansı ve sağlığ1 iyileştirdiği tespit edilmiştir (Engbers \& Hendriksen, 2010). Ulaşım ya da serbest zaman etkinliği olarak bisiklet kullanımının kişisel doyum, güvenlik algısı ve sosyal destek gibi çevresel, kişisel ya da sosyal yönleri vardır (Hendriksen et al., 2000). O'Connor \& Brown (2007) ise bisiklet kullanımının, sosyal etkileşim üzerinde de olumlu etkileri olduğu belirtmişlerdir. Bazı araştırmacılar ise bisiklet kullanmayı ciddi serbest zaman faaliyeti olarak ele almaktadırlar (O'Connor \& Brown, 2007; Brown et al., 2009). Ciddi serbest zaman, birey için son derece önemli, ilgi çekici ve doyurucu olan, amatör, hobiye ya da gönüllülük esasına dayalı, katılımcıların, özel beceri, bilgi ve tecrübe ile kariyer elde etmesini sağlayan sistematik bir uğraşıdır (Stebbins, 2007). Ciddi serbest zaman etkinliği olarak bisiklet kullanma, informal düzeyde, düzenli olarak bir grupla antrenman yapmayı ve yarısmalara katılmayı içeren, sporun yapılandırılmamış ve daha az örgütlü biçimidir (O'Connor \& Brown, 2007).

Dünyada bisiklet kullanımının yaygınlığına bakıldığında Kuzey Avrupa genel olarak, dünyanın en büyük bisiklet dostu bölgesi kabul edilmektedir. Dünyadaki diğer önemli bisiklet bölgelesi Asya Kıtası ve bu kıtada da özellikle Çin'dir. Kuzey Avrupa ve Çin'in aksine kitlesel otomobil alışkanlığı bulunan Kuzey Amerika ve Avustralya/Yeni Zellanda bölgelerinde de bisiklet kullanımına yönelik karşıt bir tavır sıklıkla göze çarpmaktadır (Horton et al., 2007). Türkiye'de bisiklet kullanıcıları ile ilgili çalışmalarda, bisiklet kullanıcı sayısının ve bu kullanıcıların hangi amaçlarla bisiklet kullandıklarının tam olarak bilinmediği yönünde ortak bir görüş vardır. Ardahan ve Mert (2014a) çalışmalarında son yıllarda bisiklet kullanımının ciddi bir biçimde arttığını belirtmişlerdir. Ancak küresel iklim değişikliği ile mücadelede yasalarda bile bisiklete yer verilse de, devlet politikalarının yetersizliği ve bisikletin otomobil sürücüleri ve diğer sürücüler tarafindan bir ulaşım aracı olarak görülmemesi, Türkiye'yi Hollanda, Danimarka, Çin ve Japonya gibi ülkelerin çok gerisinde birakmaktadir.

Günümüzde kullanım alanı çok genişlemiş olan bisikletin günlük yaşamda sağladığı avantajlarının yanı sıra bireyler, bisiklet kullanma konusunda bir takım engellerle karşılaşmaktadırlar. Engbers ve Hendriksen (2010) algılanan zaman ve mesafe gibi kişisel faktörlerin günlük bisiklet kullanımındaki başlıca engeller olduğunu belirtmişlerdir. Bunun yanında çalışmalar korkunun bisiklet kullanımında önemli bir duygusal engel olduğunu ortaya koymaktadır (Horton, 2007). Dünyada çevre dostu olan bisiklet kullanımını yaygınlaştırıcı uygulamalar hayata geçirilmeye çalışılmaktadır. Bisiklet kiralama sistemleri dünya çapında daha popüler hale gelmekte olup, yoğun kent ortamında ulaşımı sağlamak ve gezinti açısından sağlıklı, ucuz ve verimli görülmektedir (O’brien, Cheshire \& Batty, 2013).

Ho ve ark. (2015) çevre korumaya olan ilginin artması ve sürdürülebilir gelişme konusundaki farkındalı̆̆ın bisiklet kullanımını artırabileceğini belirtmişlerdir. Horton'da (2006) çalışmasında İngiltere'de bisiklet kullanımının sürdürülebilirlik açısından yeşil vizyon sahibi bir toplum oluşturmada önemli bir etken olduğunu belirtmektedir.

Araştırmacılar bireylerin bisiklet kullanma nedenlerini açıklayabilmek için pek çok sosyolojik yaklaşımdan yararlanmışlardır. Ho ve ark., (2015) bisiklet kullanıcılarının mutluluk, aidiyet, benlik sayg1sı, kendini gerçekleştirme gibi temel değerlere ulaşmak amacıyla bisiklet kullandıklarını belirtmişlerdir. Serbest zaman/rekreasyonel bisikletçilerin bu aktiviteyle uğraşma nedeni de Maslow'un beş boyutlu İhtiyaçlar Hiyerarşisi kuramına dayalı olarak kendini gerçekleştirme düzeyindeki kişisel ihtiyaçları yerine getirmek olarak açıklanmıştır (Ho et al., 2015). 
Brown ve ark. (2009) bisiklet kullanımını ciddi serbest zaman etkinliği olarak ele almış ve bisikletçiler için sosyal, kültürel, ekonomik ve ekolojik motivasyon faktörlerini, diğer motivasyonel faktörler ile ilişkilendirilerek bir motivasyon ölçeği hazırlanmışlardır. Ardahan ve Mert (2014a) tarafından geliştirilen ölçekte ise bireyleri bisiklet kullanmaya motive eden faktörler; doğayı, hızı, zor koşullarla mücadeleyi deneyimleme; taktir edilme, fark edilme, kendini gösterme; ekolojik duyarll1ık, farkındalık; ulaşım, fiziksel aktivite ve sağlık, sosyalleşme, bireyin kendiyle rekabeti, uzaklaşma ve dinlenme, örnek olma, özgürlük hissi, özgürce yiyebilme ve kilo kontrolü, coğrafik uygunluk olarak ele alınmıştır. Skår ve ark. (2008) ise dağ bisikleti kullanıcılarını bisiklet kullanmaya motive eden faktörleri fiziksel egzersiz, niyet, doğa ve yer, hız ve heyecan, zorlukları yönetme, sosyal ilişkiler, ekipman ve beğeni olarak belirtmişlerdir. Streicher ve Saayman (2010) bireyleri bisiklet kullanmaya yönelten motivasyonları sosyalizasyon, etkinliğin çekiciliği, kişisel motivasyon, kaçış ve rahatlama, etkinlik özellikleri olarak açıklamışlardır. Ritchie ve ark., (2010) bisiklet kullanıcılarının motivasyon ve seyahat davranışlarını açıklayabilmek için temelde iki boyutlu bir ölçek geliştirmişlerdir. Sürekli ilgi faktörleri olarak; hoşlanma, kendini ifade etme, merkeze alma ele alınırken, itici motivasyon faktörleri ise; macera deneyimleri, yeterlilik sağlama, kişisel mücadele, dinlenme/kaçış, sosyal buluşma olarak bildirilmiştir.

\section{Amaç}

Bireyleri bisiklet kullanma nedenlerinin ve elde ettikleri faydaların bilinmesi, bisiklet kullanımını yaygınlaştırma politikaları bakımından önem taşımaktadır. Türkiye'deki bisiklet kullanıcılarını daha iyi tanımlayabilmek gerekçesiyle, bu çalışmanın amacı; bisiklet kullanan bireylerin bu etkinliklere katılım nedenleri ve elde ettikleri faydaları ortaya koyabilmektir. Bu amaçla aşağıdaki soruları yanıt aranmışır.

1. Kat1limciları bisiklet kullanma nedenleri nedir?

2. Katılımcların bisiklet kullanma sonucu elde ettikleri faydalar nelerdir?

3. Bazı kişisel bilgilere göre (cinsiyet, medeni durum, yaş, öğrenim durumu, çalışma durumu, aylık gelir, kaç yıldır bisiklet kullandığı) katılımcıların bisiklet kullanma nedenleri ve bisiklet kullanma sonucunda elde ettikleri faydalar arasında anlamlı fark var mıdır?

\section{Materyal ve Yöntem}

\subsection{Araştırmanın Modeli}

Araştırma tarama modeli üzerine kurulmuştur. Tarama modelleri geçmişte ya da o sırada varolan durumu, olduğu biçimiyle tanımlamayı amaçlayan araştırma yaklaşımıdır (Karasar, 2007).

\subsection{Evren ve Örneklem}

Araştırmanın evrenini Türkiye'deki rekreasyonel amaçlı bisiklet kullanıcıları oluşturmaktadır. Araştırmada yer alacan bisiklet kullanıcıları kolayda örnekleme yöntemi ile seçilmiştir. Ülkemizde rekreasyonel amaçlı bisiklet kullanıcılarının sayısı net olarak bilinmemektedir. Bu nedenle Krejcie ve Morgan (1970) tarafindan değerlendirmelerin oranlara göre yapılacağı araştırmalarda evren hacminin büyüklügüne karşılık örneklem büyüklügünün 0.05 tolerans edilebilir hata için göre en üst sinırı 384 kişi olarak belirlenmiştir. Araştırmanın örneklemini ise Mayıs 2014-Nisan 2015 tarihleri arasında Türkiye'de herhangi bir bisiklet topluluğu ile bisiklet etkinliklerine katılan 606 bisiklet kullanıcısı oluşturmuştur. Buna göre araştırmaya katılan bisiklet kullanıcılarının sayısı, nicel çalışmalar için kullanılan örneklem büyüklügünü belirleme yöntemlerine göre hesaplanan alt sinırın oldukça üzerinde gerçekleşmiştir. Araştırmaya katılan bisiklet kullanıcılarının bazı kişisel özelliklerine göre dağglımı Tablo 1'de gösterilmiştir. 
Koçak, F. (2016). Türkiye'de bisiklet kullanımı: Bisiklet kullanma nedenleri ve elde edilen faydalar. Journal of Human Sciences, 13(3), 5760-5771. doi:10.14687/ihs.v13i3.4190

Tablo 1. Araştırmaya Katılan Bisiklet Kullanıcılarının Kişisel Bilgileri

\begin{tabular}{|c|c|c|c|}
\hline Kişisel Bilgiler & Alt Gruplar & $\begin{array}{l}\text { Frekans } \\
\text { (f) }\end{array}$ & $\begin{array}{c}\text { Yüzde } \\
(\%)\end{array}$ \\
\hline \multirow{3}{*}{ Cinsiyet } & Kadın & 110 & 18.2 \\
\hline & Erkek & 496 & 81.8 \\
\hline & Toplam & 606 & 100 \\
\hline \multirow{3}{*}{ Medeni Durum } & Evli & 153 & 25.2 \\
\hline & Bekar & 453 & 74.8 \\
\hline & Toplam & 606 & 100 \\
\hline \multirow{5}{*}{ Yaş } & $18-25$ yaş & 230 & 38.0 \\
\hline & $26-33$ yaş & 185 & 30.5 \\
\hline & 34-41 yaş & 110 & 18.2 \\
\hline & 42-49 yaș & 81 & 13.4 \\
\hline & Toplam & 606 & 100 \\
\hline \multirow{4}{*}{ Öğrenim Durumu } & Ortaöğretim & 178 & 29.4 \\
\hline & Üniversite & 357 & 58.9 \\
\hline & Lisansüstü & 71 & 11.7 \\
\hline & Toplam & 606 & 100.0 \\
\hline \multirow{3}{*}{ Çalışma Durumu } & Çalışıyor & 372 & 61.4 \\
\hline & Çalışmıyor & 234 & 38.6 \\
\hline & Toplam & 606 & 100 \\
\hline \multirow{5}{*}{ Aylık Gelir } & $0-900$ & 181 & 29.9 \\
\hline & $9001-1800$ & 135 & 22.3 \\
\hline & $1801-2700$ & 127 & 21.0 \\
\hline & 2701 ve üzeri & 163 & 26.9 \\
\hline & Toplam & 606 & 100 \\
\hline \multirow{4}{*}{$\begin{array}{l}\text { Bisiklet Kullanma } \\
\text { Süresi }\end{array}$} & $1-3 \mathrm{y} 1 \mathrm{l}$ & 218 & 36.0 \\
\hline & $4-6$ y1l & 108 & 17.8 \\
\hline & 7 y1l ve üzeri & 218 & 36.0 \\
\hline & Toplam & 606 & 100 \\
\hline
\end{tabular}

\subsection{Veri Toplama Arac1}

Araştırmada veri toplama yöntemi olarak anket tekniği kullanılmıştır. Araştırmada kullanılan anket konuyla ilgili literatür taranarak araştırmacı tarafindan hazırlanmıştır (Titze et al., 2007; Titze et al., 2008; Ritchie et al., 2010; Ardahan \& Yerlisu Lapa 2011; Ardahan \& Mert 2014a). Geliştirilen veri toplama aracı üç bölümden oluşmaktadır. İlk bölümde katılımcıların araştırmaya katkı sağlayacağı düşünülen bazı kişisel bilgileri belirlemeye yönelik 9 adet soru, ikinci bölümde bisiklet kullanma nedenlerini belirleye yönelik 17 madde, üçüncü bölümde ise bisiklet kullanımı sonucunda elde edilen faydaları ortaya koymak amacıyla 18 madde yer almaktadır. Üçlü Likert tipi değerlendirme ölçeğine göre 1=tam katılmıorum (1,00-1,66), $2=$ orta düzeyde kattlıyorum $(1,67$ 2,33), $3=$ katlliyorum (2,34-3.00) olarak derecelendirilmiştir. Araştırmada Ki-Kare testi kullanıldığından, hücre sayılarının teste uygunluk oranını artırmak amacıyla üçlü Likert tipi derecelendirme ölçeği kullanılmıştır.

\subsection{Verilerin Analizi}

Araştırmada bisiklet kullanıcılarının bireysel özellikleri frekans ve yüzde dağılımları ile verilmiş olup, katılımcıların bisiklet kullanma nedenleri ve bisiklet kullanımı sonucunda elde ettikleri faydalara ilişkin görüşlerini ortaya koymak amaciyla ise aritmetik ortalama ve standart sapma, frekans ve yüzde dağılımı değerleri hesaplanmıştır. Katılımcıların bisiklet kullanma nedenleri ve bisiklet kullanımı sonucunda elde ettikleri faydalara ilişkin görüşlerinin bireysel özelliklerine göre karşılaştırılmasında Ki-Kare $\left(\mathrm{X}^{2}\right.$-Chi Square) testi kullanılmıştır. Ki-Kare testi çeşitli sorulara verilen cevaplar ile soruyu cevaplayanların kişisel özellikleri arasında bir farklılık olup olmadığında kullanılmaktadır (Büyüköztürk, 2011). Araştırmada, güvenirlik analizi Cronbach's Alpha iç tutarlık katsayısıyla belirlenmiştir. Buna göre, Cronbach's Alpha iç tutarlık katsayısı katılımcıların bisiklet kullanma nedenleri için .875 , bisiklet kullanımı sonucunda elde 
Koçak, F. (2016). Türkiye'de bisiklet kullanımı: Bisiklet kullanma nedenleri ve elde edilen faydalar. Journal of Human Sciences, 13(3), 5760-5771. doi:10.14687/ihs.v13i3.4190

ettikleri faydalar için ise .842 olarak hesaplanmışır. İlgili literatüre göre (Nunnally \& Bernstein 1994) bu değerler veri toplama aracının güvenilir olduğunu göstermektedir. Araştırmada hata payı 0.05 olarak kabul edilmiştir.

\section{Bulgular}

Katılımciların bisiklet kullanma nedenlerine ve bisiklet kullanımı sonucunda elde ettikleri faydalara ilişkin betimsel istatistikler Tablo 2'de verilmiştir.

Tablo 2. Katılımcıların Bisiklet Kullanma Nedenleri ve Bisiklet Kullanımından Elde Ettikleri Faydalara İlişkin Görüşlerinin Ortalama ve Standart Sapma Değerleri

\begin{tabular}{|c|c|c|c|c|c|c|}
\hline \multicolumn{2}{|r|}{ Bisiklet kullanma nedenleri } & \multirow{2}{*}{$\begin{array}{l}\bar{X} \\
2.858 \\
\end{array}$} & \multirow{2}{*}{$\begin{array}{l}\text { Ss } \\
.422 \\
\end{array}$} & $\begin{array}{l}\text { Bisiklet kullanımından elde edilen } \\
\text { faydalar }\end{array}$ & \multirow{2}{*}{$\begin{array}{c}\bar{X} \\
2.953 \\
\end{array}$} & \multirow{2}{*}{$\begin{array}{c}\text { Ss } \\
.232 \\
\end{array}$} \\
\hline 1 & Doğayla bütünleşme & & & $1 \quad$ Daha mutlu hissederim & & \\
\hline 2 & Sağlı̆̆ımı korumak & 2.899 & .361 & $\begin{array}{l}\text { Daha sağlıklı ve güçlü } \\
\text { hissederim }\end{array}$ & 2.965 & .208 \\
\hline 3 & $\begin{array}{l}\text { İlgi alanım olması, bana } \\
\text { hitap etmesi }\end{array}$ & 2.866 & .402 & $\begin{array}{l}\text { İyi bir fiziksel görünüme sahip } \\
\text { olurum }\end{array}$ & 2.787 & .513 \\
\hline 4 & $\begin{array}{ll}\text { Sikıntıdan kurtulmak ve } \\
\text { stres atmak }\end{array}$ & 2.802 & .501 & Yeni kişilerle tanışırım & 2.542 & .706 \\
\hline 5 & Rutinden kurtulma isteği & 2.742 & .577 & Yeni şeyler öğrenirim & 2.696 & .594 \\
\hline 6 & Rahatlamak & 2.887 & .359 & Kendime güvenim artar & 2.724 & .587 \\
\hline 7 & İ̀s verimimi arttırdığı için & 2.387 & .790 & Kişisel tatmin elde ederim & 2.765 & .543 \\
\hline 8 & $\begin{array}{l}\text { Arkadaşlarımla beraber } \\
\text { olma isteği }\end{array}$ & 2.503 & .733 & Çevre bilinci kazanırım & 2.835 & .455 \\
\hline 9 & Yeni beceriler edinme isteği & 2.425 & .775 & Daha verimli çalışırım & 2.640 & .639 \\
\hline 10 & $\begin{array}{l}\text { Kolayca bir arkadaş } \\
\text { grubuna katılmak }\end{array}$ & 2.193 & .860 & $\begin{array}{l}\text { Bir gruba ait olma duygusunu } \\
\text { yaşarım }\end{array}$ & 2.412 & .791 \\
\hline 11 & Çevremdekilerin etkisi & 2.021 & .885 & Hayal gücüm artar & 2.493 & .764 \\
\hline 12 & Aileme iyi örnek olmak & 2.221 & .877 & $\begin{array}{l}\text { Kendimi daha önemli } \\
\text { hissederim }\end{array}$ & 2.404 & .794 \\
\hline 13 & Yalnızlıktan kurtulmak & 1.952 & .882 & Yeni iş bağlantıları kurarım & 1.988 & .904 \\
\hline & Bisiklet sporunu sevmek & 2.901 & .368 & $\begin{array}{lll}\begin{array}{l}\text { Sağliksiz } \\
\text { dururum }\end{array} & \text { besinlerden uzak } \\
\end{array}$ & 2.429 & .774 \\
\hline 15 & $\begin{array}{l}\text { Serbest zamanlarımı } \\
\text { değerlendirmek }\end{array}$ & 2.752 & .549 & Günün stresini atarım & 2.863 & .417 \\
\hline 16 & Ulaşım kolaylığ1 sağlaması & 2.800 & .499 & İstediğim yere kolayca ulaşırım & 2.793 & .506 \\
\hline 17 & Gezmek & 2.937 & .268 & $\begin{array}{l}\text { Kendimi daha kolay ifade } \\
\text { ederim }\end{array}$ & 2.363 & .807 \\
\hline & & & & Toplumsal statüm artar & 2.143 & .889 \\
\hline
\end{tabular}

Tablo 2'de araştırmaya katılan bisiklet kullanıcılarının bisiklet kullanma nedenleri ve bisiklet kullanımından elde ettikleri faydalara ilişkin görüşlerinin ortalama ve standart sapma değerleri verilmiştir. Buna göre her iki bölümde de bisiklet kullanıcılarının görüşleri orta düzeyde katıllyorum ve katıllyorum düzeyinde bulunmuştur. Katılımcıların bisiklet kullanma nedenleri bölümünde en çok katıldıkları ilk üç madde "Gezmek ( $\overline{\mathrm{X}}=2,937 \pm, 268)$ ", "Bisiklet sporunu sevmek ( $\overline{\mathrm{X}}$ $=2,901 \pm, 368)$ " ve "Sağllğımı korumak $(\overline{\mathrm{x}}=2,899 \pm, 361)$ " maddeleridir. Katılımcıların bisiklet kullanma nedenleri bölümünde en az katıldıkları üç madde "Yalnızlıktan kurtulmak ( $\overline{\mathrm{x}}$ $=1,952 \pm, 882)$ ", "Çevremdekilerin etkisi $(\overline{\mathrm{x}}=2,021 \pm, 885)$ " ve "Kolayca bir arkadaş grubuna katilmak ( $\overline{\mathrm{X}}=2,193 \pm, 860)$ " maddeleridir.

Katılımcıların bisiklet kullanımından elde edilen faydalar bölümünde en çok katıldıkları ilk üç madde "Daha sağlıklı ve güçlü hissederim ( $\overline{\mathrm{X}}=2,965 \pm 208)$, "Daha mutlu hissederim ( $\overline{\mathrm{X}}$ $=2,953 \pm, 232)$ ", "Günün stresini atarım $(\overline{\mathrm{X}}=2,863 \pm, 417)$ " maddeleridir. Katllımciların bisiklet kullanımından elde edilen faydalar bölümünde en az katıldıkları üç madde "Yeni iş bağlantıları 
Koçak, F. (2016). Türkiye'de bisiklet kullanımı: Bisiklet kullanma nedenleri ve elde edilen faydalar. Journal of Human Sciences, 13(3), 5760-5771. doi:10.14687/ihs.v13i3.4190

kurarım ( $\overline{\mathrm{X}}=1,988 \pm, 904)$ ", “Toplumsal statüm $\operatorname{artar}(\overline{\mathrm{X}}=2,143 \pm, 889)$ )" ve "Kendimi daha kolay ifade ederim $(\overline{\mathrm{X}}=2,363 \pm, 807)$ " maddeleridir.

Araştırmada, Ki-Kare testi sonucunda bisiklet kullanıcılarının bisiklet kullanma nedenleri ve bisiklet kullanımı sonucunda elde ettikleri faydaların cinsiyete, çalsşma durumuna ve bisiklet kullanma süresine göre anlamlı farklılık göstermediği tespit edilmiştir ( $>>0,05)$.

Katılımcıların medeni durumlarına göre bisiklet kullanma nedenlerine ve bisiklet kullanımı sonucunda elde ettikleri faydalara ilişkin yapılan Ki-Kare testi sonucu anlamlı çıkan maddelere ilişkin bulgular Tablo 3'de gösterilmiştir.

Tablo 3. Katllımcların Medeni Durumlarına Göre Bisiklet Kullanma Nedenlerine ve Bisiklet Kullanımı Sonucunda Elde Ettikleri Faydalara İlşkin Sonuçlar

\begin{tabular}{|c|c|c|c|c|c|c|c|c|}
\hline \multirow{3}{*}{ Maddeler } & \multirow{3}{*}{$\begin{array}{l}\text { Medeni } \\
\text { Durum }\end{array}$} & \multicolumn{2}{|c|}{ Kat1lmiyorum } & \multirow{2}{*}{\multicolumn{2}{|c|}{$\begin{array}{c}\text { Orta } \\
\text { Düzeyde } \\
\text { Katılıyorum }\end{array}$}} & \multicolumn{2}{|c|}{ Tam } & \multirow{3}{*}{$\begin{array}{c}\mathbf{X}^{2} \\
P\end{array}$} \\
\hline & & \multirow[b]{2}{*}{$\mathrm{f}$} & \multirow[b]{2}{*}{$\%$} & & & \multicolumn{2}{|c|}{ Kat1lyorum } & \\
\hline & & & & $\mathrm{f}$ & $\%$ & $\mathrm{f}$ & $\%$ & \\
\hline \multicolumn{9}{|l|}{ Bisiklet Kullanma Nedenleri } \\
\hline \multirow{2}{*}{$\begin{array}{l}\text { 3. İlgi alanım olmas1, bana hitap } \\
\text { etmesi }\end{array}$} & Evli & 1 & 0.7 & 20 & 13.1 & 132 & 86.3 & 6.975 \\
\hline & Bekar & 13 & 2.9 & 33 & 7.3 & 407 & 89.8 & .031 \\
\hline \multirow[t]{2}{*}{ 4. S1kıntıdan kurtulmak ve stres atmak } & Evli & 11 & 7.2 & 23 & 15.0 & 119 & 77.8 & 7.995 \\
\hline & Bekar & 17 & 3.8 & 41 & 9.1 & 395 & 87.2 & .018 \\
\hline \multirow[t]{2}{*}{ 12. Aileme iyi örnek olmak } & Evli & 146 & 32.2 & 91 & 20.1 & 216 & 47.7 & 13.434 \\
\hline & Bekar & 35 & 22.9 & 19 & 12.4 & 99 & 64.7 & .001 \\
\hline \multirow[t]{2}{*}{ 16. Ulaşım kolaylığı sağlaması } & Evli & 15 & 9.8 & 24 & 15.7 & 114 & 74.5 & 19.522 \\
\hline & Bekar & 12 & 2.6 & 43 & 9.5 & 398 & 87.9 & .000 \\
\hline \multicolumn{9}{|c|}{ Bisiklet Kullanmanın Sağladığı Faydalar } \\
\hline \multirow[t]{2}{*}{ 16. İstediğim yere kolayca ulaşırım } & Evli & 13 & 8.5 & 24 & 15.7 & 116 & 75.8 & 11.609 \\
\hline & Bekar & 15 & 3.3 & 45 & 9.9 & 393 & 86.8 & .003 \\
\hline
\end{tabular}

Tablo 3 incelendiğinde, katılımcıların bisiklet kullanma nedenleri bölümünde, "İlgi alanım olmas1, bana hitap etmesi $\left(X^{2}=6,975 ; p=, 031\right)$ " "Sikıntudan kurtulmak ve stres atmak $\left(X^{2}=7,995\right.$; $\mathrm{p}=, 018)$ " "Aileme iyi örnek olmak $\left(\mathrm{X}^{2}=13,434 ; \mathrm{p}=, 001\right)$ ", "Ulaşım kolaylı̆̆1 sağlaması $\left(X^{2}=19,522\right.$; $\mathrm{p}=, 000)$ " maddelerine, bisiklet kullanımı sonucunda elde ettikleri faydalar bölümünde ise "İstediğim yere kolayca ulaşırım $\left(X^{2}=11,6097 ; p=, 003\right)$ " maddesine verdikleri yanttlar ile medeni durumları arasında istatiksel olarak anlamlı fark tespit edilmiştir. Buna göre bekarların görüşleri evlilere göre daha olumludur.

Katılımcıların yaşlarına göre bisiklet kullanma nedenlerine ve bisiklet kullanımı sonucunda elde ettikleri faydalara ilişkin yapılan Ki-Kare testi sonucu anlamlı çıkan maddelere ilişkin bulgular Tablo 4'de gösterilmiştir.

Tablo 4. Katılımcıların Yaşlarına Göre Bisiklet Kullanma Nedenlerine ve Bisiklet Kullanımı Sonucunda Elde Ettikleri Faydalara İlişkin Sonuçlar

\begin{tabular}{|c|c|c|c|c|c|c|c|c|}
\hline \multirow[t]{2}{*}{ Maddeler } & \multirow[t]{2}{*}{ Yaş } & \multicolumn{2}{|c|}{ Katılmiyorum } & \multicolumn{2}{|c|}{$\begin{array}{c}\text { Orta Düzeyde } \\
\text { Katıllyorum }\end{array}$} & \multicolumn{2}{|c|}{$\begin{array}{c}\text { Tam } \\
\text { Kat1lyorum } \\
\end{array}$} & \multirow{2}{*}{$\begin{array}{c}\mathbf{X}^{2} \\
P\end{array}$} \\
\hline & & $\mathrm{f}$ & $\%$ & $\mathrm{f}$ & $\%$ & $\mathrm{f}$ & $\%$ & \\
\hline \multicolumn{9}{|l|}{ Bisiklet Kullanma Nedenleri } \\
\hline \multirow{5}{*}{$\begin{array}{l}\text { 4. Sikıntıdan kurtulmak ve } \\
\text { stres atmak }\end{array}$} & 18 yaş altı & 2 & 8.3 & 1 & 4.2 & 21 & 87.5 & \multirow{5}{*}{$\begin{array}{c}17.685 \\
.024\end{array}$} \\
\hline & $18-25$ yaş & 6 & 2.9 & 20 & 9.7 & 180 & 87.4 & \\
\hline & $26-33$ yaş & 5 & 2.7 & 19 & 10.3 & 161 & 87.0 & \\
\hline & $34-41$ yaş & 5 & 4.5 & 16 & 14.5 & 89 & 80.9 & \\
\hline & 42 ve üstü & 10 & 12.3 & 8 & 9.9 & 63 & 77.8 & \\
\hline \multirow{5}{*}{ 12. Aileme iyi örnek olmak } & 18 yaş altı & 4 & 16.7 & 10 & 41.7 & 10 & 41.7 & \multirow{5}{*}{$\begin{array}{c}19.645 \\
.012\end{array}$} \\
\hline & $18-25$ yaş & 64 & 31.1 & 36 & 17.5 & 106 & 51.5 & \\
\hline & $26-33$ yaş & 65 & 35.1 & 32 & 17.3 & 88 & 47.6 & \\
\hline & 34-41 yaş & 24 & 21.8 & 24 & 21.8 & 62 & 56.4 & \\
\hline & 42 ve üstü & 24 & 29.6 & 8 & 9.9 & 49 & 60.5 & \\
\hline
\end{tabular}


Katılımcıların bisiklet kullanma nedenleri bölümünde, "Sıkıntıdan kurtulmak ve stres atmak $\left(X^{2}=17,685 ; p=, 024\right)$ " ve "Aileme iyi örnek olmak $\left(X^{2}=19,645 ; p=, 012\right)$ " maddelerine verdikleri yanıtlar ile yaşları arasında istatiksel olarak anlamlı fark tespit edilmiştir. Buna göre sıkıntıdan kurtulmak stres atmak maddesine 42 yaş ve üzerindekiler diğer yaş gruplarına göre daha az katılmaktadırlar. 18 yaşın altındaki bisikletçilerin diğer yaş gruplarına göre "Aileme iyi örnek olmak" maddesine daha çok katıldıkları görülmüştür.

Katılımcıların öğrenim durumlarına göre bisiklet kullanma nedenlerine ve bisiklet kullanımı sonucunda elde ettikleri faydalara ilişkin yapılan Ki-Kare testi sonucu anlamlı çıkan maddelere ilişkin bulgular Tablo 5'de gösterilmiştir.

Katılımcıların bisiklet kullanma nedenleri bölümünde, "Ulaşım kolaylığı sağlaması $\left(\mathrm{X}^{2}=11,549 ; \mathrm{p}=, 021\right)$ " maddesine ve bisiklet kullanımı sonucunda elde ettikleri faydalar bölümünde ise "İyi bir fiziksel görünüme sahip olurum $\left(\mathrm{X}^{2}=9,734 ; \mathrm{p}=, 045\right)$ ", "Yeni iş bağlantıları kurarım $\left(X^{2}=10,662 ; p=, 031\right)$ ", "Sağliksız besinlerden uzak dururum $\left(X^{2}=9,614 ; p=, 047\right)$ " maddelerine verdikleri yanıtlar ile öğrenim durumları arasında anlamlı fark tespit edilmiştir. Ortaöğretim mezunları yukarıdaki maddelerde lisansüstü ve üniversite mezunlarına göre daha olumlu düşünmektedirler.

Tablo 5. Katulımcıların Ögrrenim Durumlarına Göre Bisiklet Kullanma Nedenlerine ve Bisiklet Kullanımı Sonucunda Elde Ettikleri Faydalara İlişkin Sonuçlar

\begin{tabular}{|c|c|c|c|c|c|c|c|c|}
\hline \multirow[t]{2}{*}{ Maddeler } & \multirow{2}{*}{$\begin{array}{l}\text { Öğrenim } \\
\text { Durumu }\end{array}$} & \multicolumn{2}{|c|}{ Katılmiyorum } & \multicolumn{3}{|c|}{$\begin{array}{l}\text { Orta Düzeyde } \\
\text { Kat1liyorum }\end{array}$} & \multirow{2}{*}{$\begin{array}{c}\begin{array}{c}\text { Tam } \\
\text { Kat1liyorum }\end{array} \\
\%\end{array}$} & \multirow{2}{*}{$\begin{array}{c}\mathbf{X}^{2} \\
P\end{array}$} \\
\hline & & $\mathrm{f}$ & $\%$ & $\mathrm{f}$ & $\%$ & $\mathrm{f}$ & & \\
\hline \multicolumn{9}{|l|}{ Bisiklet Kullanma Nedenleri } \\
\hline \multirow{4}{*}{$\begin{array}{l}\text { 3. İlgi alanım olması, bana } \\
\text { hitap etmesi }\end{array}$} & Ortaöğretim & 9 & 5.1 & 1 & 6.7 & 157 & 88.2 & \multirow{4}{*}{$\begin{array}{c}11.549 \\
.021\end{array}$} \\
\hline & & & & 2 & & & & \\
\hline & Üniversite & 3 & 0.8 & $\begin{array}{l}3 \\
2\end{array}$ & 9.0 & 322 & 90.2 & \\
\hline & Lisansüstü & 2 & 2.8 & 9 & 12.7 & 60 & 84.5 & \\
\hline \multicolumn{9}{|c|}{ Bisiklet Kullanmanın Sağladığı Faydalar } \\
\hline \multirow{4}{*}{$\begin{array}{l}\text { 3. İyi bir fiziksel görünüme } \\
\text { sahip olurum }\end{array}$} & Ortaöğretim & 14 & 7.9 & 1 & 7.3 & 151 & 84.8 & \multirow{4}{*}{$\begin{array}{l}9.734 \\
.045\end{array}$} \\
\hline & & & & 3 & & & & \\
\hline & Üniversite & 12 & 3.4 & $\begin{array}{l}5 \\
0\end{array}$ & 14.0 & 295 & 82.6 & \\
\hline & Lisansüstü & 3 & 4.2 & 8 & 11.3 & 60 & 84.5 & \\
\hline \multirow{4}{*}{ 13. Yeni iş bağlantıları kurarım } & Ortaöğetim & 67 & 37.6 & 2 & 15.7 & 83 & 46.6 & \multirow{4}{*}{$\begin{array}{c}10.662 \\
.031\end{array}$} \\
\hline & & & & 8 & & & & \\
\hline & Üniversite & 144 & 40.3 & $\begin{array}{l}7 \\
3 \\
\end{array}$ & 20.4 & 140 & 39.2 & \\
\hline & Lisansüstü & 40 & 56.3 & $\begin{array}{l}1 \\
0\end{array}$ & 14.1 & 21 & 29.6 & \\
\hline \multirow{3}{*}{$\begin{array}{l}\text { 14. Sağlıksız besinlerden uzak } \\
\text { dururum }\end{array}$} & Ortaöğretim & 28 & 15.7 & $\begin{array}{l}3 \\
1\end{array}$ & 17.4 & 119 & 66.9 & \multirow{3}{*}{$\begin{array}{l}9.614 \\
.047\end{array}$} \\
\hline & Üniversite & 68 & 19.0 & $\begin{array}{l}7 \\
7\end{array}$ & 21.6 & 212 & 59.4 & \\
\hline & Lisansüstü & 11 & 15.5 & $\begin{array}{l}2 \\
4\end{array}$ & 33.8 & 36 & 50.7 & \\
\hline
\end{tabular}

$P<0,05$

Bisiklet kullanıcılarının gelir durumlarına göre bisiklet kullanma nedenlerine ve bisiklet kullanımı sonucunda elde ettikleri faydalara ilişkin yapılan Ki-Kare testi sonucu anlamlı çıkan maddelere ilişkin bulgular Tablo 6'de gösterilmiştir. 
Koçak, F. (2016). Türkiye'de bisiklet kullanımı: Bisiklet kullanma nedenleri ve elde edilen faydalar. Journal of Human Sciences, 13(3), 5760-5771. doi:10.14687/jhs.v13i3.4190

Tablo 6. Katıllmciların Gelir Durumlarına Göre Bisiklet Kullanma Nedenlerine ve Bisiklet Kullanımı Sonucunda Elde Ettikleri Faydalara İlişkin Sonuçlar

\begin{tabular}{|c|c|c|c|c|c|c|c|c|}
\hline \multirow[t]{2}{*}{ Maddeler } & \multirow[t]{2}{*}{$\begin{array}{l}\text { Gelir Durumu } \\
\text { (TL) }\end{array}$} & \multicolumn{2}{|c|}{ Katılmiyorum } & \multicolumn{2}{|c|}{$\begin{array}{l}\text { Orta Düzeyde } \\
\text { Kat1liyorum }\end{array}$} & \multicolumn{2}{|c|}{$\begin{array}{c}\text { Tam } \\
\text { Kat1liyorum }\end{array}$} & \multirow{2}{*}{$\begin{array}{c}\mathbf{X}^{2} \\
P\end{array}$} \\
\hline & & f & $\%$ & $\mathrm{f}$ & $\%$ & $\mathrm{f}$ & $\%$ & \\
\hline \multicolumn{9}{|c|}{ Bisiklet Kullanmanın Sağladığı Faydalar } \\
\hline \multirow{4}{*}{$\begin{array}{l}\text { 16. İstediğim yere kolayca } \\
\text { ulaşırım }\end{array}$} & $0-900$ & 5 & 2.8 & 17 & 9.4 & 159 & 87.8 & \multirow{4}{*}{$\begin{array}{c}20.939 \\
.002\end{array}$} \\
\hline & $901-1800$ & 6 & 4.4 & 7 & 5.2 & 122 & 90.4 & \\
\hline & $1801-2700$ & 4 & 3.1 & 25 & 19.7 & 98 & 77.2 & \\
\hline & 2701 ve üzeri & 13 & 8.0 & 20 & 12.3 & 130 & 79.8 & \\
\hline
\end{tabular}

Katılımcıların bisiklet kullanımı sonucunda elde ettikleri faydalar bölümünde, "İstediğim yere kolayca ulaşırım" maddesine verdikleri yantlar ile gelir durumları arasında istatiksel olarak anlamlı fark tespit edilmiştir $\left(X^{2}=20,939 ; p=, 002\right)$. Buna göre 0-900 ve 901-1800 lira aylik gelire sahip bisiklet kullanıcıları, daha yüksek gelir grubundakilere göre daha olumlu düşünmektedirler.

\section{Tartışma ve Sonuç}

$\mathrm{Bu}$ araştırmada bireylerin bisiklet kullanma nedenleri ve bisiklet kullanımından elde ettikleri faydalar; cinsiyet, medeni durum, yaş, öğrenim durumu, çalışma durumu, aylık gelir, kaç yıldır bisiklet kullandığ1 gibi kişisel değişkenlere göre değerlendirilmiştir. Bireylerin bisiklet kullanmalarındaki ilk üç neden gezmek, bisiklet sporunu sevmek ve sağlığ korumak olarak tespit edilmiştir. Ho ve ark., (2015) bisiklet kullanıcılarının mutluluk, aidiyet, benlik saygısı, kendini gerçekleştirme gibi temel değerlere ulaşmak amacıyla bisiklet kullandıklarını belirtmişlerdir. Ardahan ve Mert (2014b) tarafindan yapılan çalışmada ise araştırmaya katılan bireylerin önemli bir kısmı, bisiklet kullanma nedenlerinin sosyal/rekreatif ve ulaşım amaçlı olduğunu belirtmişlerdir.

Katılımcıların bisiklet kullanımından elde edilen faydalar bölümünde en çok katıldıkları ilk üç madde, daha sağlıklı ve güçlü hissederim, daha mutlu hissederim, günün stresini atarım maddeleridir. Bireyler, bisiklet kullanımı sonucu hem fiziksel hem de psikolojik olarak kendilerini daha sağlıklı hissetmektedirler. Bu durum bisiklet kullanımının sağlı̆̆a olan katkılarının (Oja et al., 2011) bireyler tarafindan da hissedildiğini göstermektedir.

Araştırmada bisiklet kullanıcılarının bisiklet kullanma nedenleri ve bisiklet kullanımı sonucunda elde ettikleri faydaların cinsiyete, çalışma durumuna ve bisiklet kullanma süresine göre anlamlı farklılık göstermediği tespit edilmiştir. Herman (2015) tarafindan bisikletçiler üzerinde yapılan çalışmada da kadın ve erkek bisikletçilerin bisiklet kullanma nedenleri arasında anlamlı farklılık bulunmamıştır. Bu gruplarda farklılığın olmaması bisiklet sporunun toplumun her kesimine hitap eden bir spor olduğunu göstermektedir.

Katılımcıların öğrenim durumlanına göre bisiklet kullanma nedenleri bölümünde, "ulaşım kolaylığı sağlaması" maddesi ve bisiklet kullanımı sonucunda elde ettikleri faydalar bölümünde, "iyi bir fiziksel görünüme sahip olurum”, “yeni iş bağlantıları kurarım”, sağlıksız besinlerden uzak dururum" maddelerine ilişkin görüşleri arasında anlamlı fark vardır. Ortaöğretim mezunları yukarıdaki maddelerde lisansüstü ve üniversite mezunlarına göre daha olumlu düşünmektedirler. Bisikletin kolay ulaşılabilir ve ekonomik bir ulaşım aracı olmasının yanında, bisiklet kullanmanın bireylerin sağllğını korumaya yönelik yaptığı olumlu katkılar günümüzde sıklıkla dile getirilmektedir. Bireylerin açık hava rekreasyon aktivitelerine katılımlarında en önemli belirleyicilerden ikisi öğrenim durumu ve gelir durumudur (Shores et al., 2007). Ancak bisikletin kolay ulaşllabilir ve ekonomik bir ulaşım aracı olmasından dolayı düşük gelir ve öğrenim düzeyindeki bireylerin motivasyonu daha fazla olabilir. Bu durum Ardahan ve Mert (2014b) tarafindan yapılan çalışmada da desteklenmektedir. Ardahan ve Mert (2014b) üniversite ve lisansüstü mezunlanının bisiklet motivasyonlarının daha az olduğu bulmuşlardır.

Katılımcıların bisiklet kullanımı sonucunda elde ettikleri faydalar bölümünde, "istediğim yere kolayca ulaşırım" maddesine verdikleri yanıtlar ile gelir durumlanı arasında istatiksel olarak anlamlı fark tespit edilmiştir. Buna göre 0-900 ve 901-1800 lira aylık gelire sahip bisiklet kullanıcıları, 
daha yüksek gelir grubundakilere göre daha olumlu düşünmektedirler. Düşük gelir düzeyi serbest zaman etkinliklerine kat1lımda engel oluşturabilmektedir (Brown et al., 2001). Ancak bisikletin ulaşımda da kullanılmasından dolayı gelir seviyesi düşük bireyler tarafindan tercih edilme olasılığı artabilir. Gelir seviyesi artıkça bisikletin ulaşımdaki rolü de azalabilir. Çünkü bisiklet en ekonomik ulaşım aracıdır ve bireyler gelirleri arttıkça araba sahibi olabilirler ya da ulaşıma daha kolay para harcayabilirler.

Evli ve bekar katılımcıların bisikletten elde ettikleri faydalara bakıldığında, bekar bisiklet kullanıcıların daha fazla fayda sağladıkları görülmüştür. Arhan ve Mert (2014b) tarafindan yapılan çalışmada da bekarların bisiklet kullanımına yönelik motivasyonları evlilere göre daha yüksek bulunmuştur. Bekarların bisiklet kullanımından daha fazla fayda sağlamalarının nedeni, evlilerin aile ortamında otomobil kullanmını daha faydalı buluyor olmalarından kaynaklanabilir. Ancak bu bulguların tam tersine Ardahan ve Yerlisu Lapa (2011) evlilerin bekarlara oranla doğa sporuna katılımda daha fazla motive olduklarını tespit etmişlerdir.

Sonuç olarak; katılımcılar bisiklet kullanma nedenleri, gezmek, bisiklet sporunu sevmek ve sağlığı korumak olarak belirtirken, elde ettikleri faydaları ise daha sağlıklı ve güçlü hissetmek, daha mutlu hissetmek ve günün stresini atmak olarak belirtmişlerdir. Gelir düzeyi ve eğitim düzeyinin artması bisiklet kullanımına yönelik olumlu görüşleri azaltırken, bekarların evlilere göre görüşlerinin daha olumlu olduğu görülmüştür. Bununla birlikte cinsiyet, çalışma durumu ve bisiklet kullanma süresi bireylerin bisiklet kullanımını etkilememektedir.

Bisiklet kullanımı her yaştan ve toplumun her kesiminden bireyin kattlabileceği bir etkinliktir. Bisikletin bireye sağladığı faydalar düşünüldüğünde kuşkusuz ki Türkiye’de bisiklet kullanımının yaygınlaştırılması gerekmektedir. Bekarların olduğu kadar evlilerin de bisiklet kullanımından elde ettikleri faydaları artırmak amacıyla ailelerin güvenli ve pratik olarak bisiklete binmeleri için gerekli ortamların hazırlanması gerekmektedir. Bu anlamda yerel yönetimler, üniversiteler, eğitim ve spor kurumlarına büyük görevler düşmektedir. Bisiklet kullanımının yaygınlaşması için çeşitli etkinlikler düzenlenmeli, bireylerin bisikletle tanışması sağlanmalıdır. Ayrıca akademik çalışmaları artırmak amacıyla literatürde yer alan diğer bisiklet motivasyon ölçeklerinin Türkçe'ye uyarlanması da önem taşımaktadır.

\section{Kaynaklar}

Ardahan, F., \& Yerlisu Lapa, T. (2011). Açık alan rekreasyonu: bisiklet kullanıcıları ve yürüyüşçülerin doğa sporu yapma nedenleri ve elde ettikleri faydalar. Uluslararası İnsan Bilimleri Dergisi, 8(1), 1327-1341.

Ardahan, F. Mert, M. (2014a). Bireyleri bisiklet kullanmaya motive eden faktörler ölçeğinin geliştirilmesi ve Türk popülasyonu için güvenirlilik geçerlilik çalışması, Akademik Sosyal Arastirmalar Dergisi, 2(1), 409-427.

Ardahan, F. Mert, M. (2014b). Bisiklet Kullanan Bireylerin Profillerinin Belirlenmesi ve Bireyleri Bisiklet Kullanmaya Motive Eden Faktörlerin Çeşitli Demografik Değişkenlere Göre Değerlendirilmesi: Türkiye Örneği. Turkiye Klinikleri Journal of Sports Sciences, 6(2), 53-67.

Brown, P. R., Brown, W. J., Miller, Y. D., \& Hansen, V. (2001). Perceived constraints and social support for active leisure among mothers with young children. Leisure Sciences, 23, 131144. View Article: DOI: http://dx.doi.org/10.1080/014904001316896837

Brown, T. D., O'Connor, J. P., \& Barkatsas, A. N. (2009). Instrumentation and motivations for organised cycling: the development of the Cyclist Motivation Instrument (CMI). Journal of sports science and medicine, 8(2), 211-218.

Büyüköztürk, Ş. (2011). Sosyal bilimler için veri analizi el kitab1. 13. Bask1, Ankara: Pegem Akademi.

Daley, M., \& Rissel, C. (2011). Perspectives and images of cycling as a barrier or facilitator of cycling. Transport policy, 18(1), 211-216. View Article: DOI: http://dx.doi.org/10.1016/j.tranpol.2010.08.004

Engbers, L. H., \& Hendriksen, I. J. (2010). Characteristics of a population of commuter cyclists in the Netherlands: perceived barriers and facilitators in the personal, social and physical 
Koçak, F. (2016). Türkiye'de bisiklet kullanımı: Bisiklet kullanma nedenleri ve elde edilen faydalar. Journal of Human Sciences, 13(3), 5760-5771. doi:10.14687/ihs.v13i3.4190

environment. International Journal of Behavioral Nutrition and Physical Activity, 7(5), 89-93. View Article: DOI: $10.1186 / 1479-5868-7-89$

Hendriksen, I. J., Zuiderveld, B. O. B., Kemper, H. C., \& Bezemer, P. D. (2000). Effect of commuter cycling on physical performance of male and female employees. Medicine and science in sports and exercise, 32(2), 504-510.

Herman, Z. T. (2015). Serious Leisure and Leisure Motivations Among Self-identified Cyclists. Journal of Tourism and Hospitality Management, 3(1-2), 32-40. View Article: DOI: 10.17265/2328-2169/2015.02.004

Ho, C. I., Liao, T. Y., Huang, S. C., \& Chen, H. M. (2015). Beyond environmental concerns: using means-end chains to explore the personal psychological values and motivations of leisure/recreational cyclists. Journal of Sustainable Tourism, 23(2), 234-254. View Article: DOI: http://dx.doi.org/10.1080/09669582.2014.943762

Horton, D. (2006). Environmentalism and the bicycle. Environmental Politics,15(1), 41-58. View Article: DOI: $10.1080 / 09644010500418712$

Horton, D., (2007). Fear of Cycling. In: Horton, D., Rosen, P., Cox, P. (Eds.), Cycling and Society. Hampshire, England, pp. 134-152.

Horton, D., Cox, P., Rosen, P., (2007). Cycling and Society. In: Horton, D., Rosen, P., Cox, P. (Eds.), Cycling and Society. Hampshire, England, pp. 1-23.

Karasar, N. (2007). Bilimsel araştırma yöntemi. 17. Baskı, Ankara: Nobel Yayın Dağıtım.

Krejcie, R. V., \& Morgan, D. W. (1970). Determining sample size for research activities. Educational and Psychological Measurement. 30(3), 607-610.

Nunnally, J. C., \& Bernstein, I. H. (1994). The assessment of reliability. In Psychometric Theory, 3rd Edition. Chapter 7, New York: McGraw Hill. pp. 248-292.

O’Brien, O., Cheshire, J., \& Batty, M. (2014). Mining bicycle sharing data for generating insights into sustainable transport systems. Journal of Transport Geography, 34, 262-273. View Article: DOI: http://dx.doi.org/10.1016/j.jtrangeo.2013.06.007

O'Connor, J. P., \& Brown, T. D. (2007). Real Cyclists Don't Race Informal Affiliations of the Weekend Warrior. International Review for the Sociology of Sport, 42(1), 83-97. View Article: DOI: 10.1177/1012690207081831

Oja, P., Titze, S., Bauman, A., De Geus, B., Krenn, P., Reger-Nash, B., \& Kohlberger, T. (2011). Health benefits of cycling: a systematic review. Scandinavian journal of medicine \& science in sports, 21(4), 496-509. View Article: DOI: 10.1111/j.1600-0838.2011.01299.x

Ritchie, B. W., Tkaczynski, A., \& Faulks, P. (2010). Understanding the motivation and travel behavior of cycle tourists using involvement profiles. Journal of Travel \& Tourism Marketing, 27(4), 409-425. View Article: DOI: http://dx.doi.org/10.1080/10548408.2010.481582

Shores, K. A., Scott, D., \& Floyd, M. F. (2007). Constraints to outdoor recreation: A multiple hierarchy stratification perspective. Leisure Sciences, 29(3), 227-246. View Article: DOI: http://dx.doi.org/10.1080/01490400701257948

Skår, M., Odden, A., \& Inge Vistad, O. (2008). Motivation for mountain biking in Norway: Change and stability in late-modern outdoor recreation. Norsk Geografisk. Tidsskrift-Norwegian Journal of Geography, 62(1), 36-45. View Article: http://dx.doi.org/10.1080/00291950701865101

Stebbins, R. A. (2007). Serious leisure: A perspective for our time. New Brunswick: Transaction Publishers.

Streicher, H., \& Saayman, M. (2010). Travel motives of participants in the Cape Argus Pick n Pay Cycle Tour. South African Journal for Research in Sport, Physical Education and Recreation, 32(1), 121-131. View Article: DOI: http://dx.doi.org/10.4314/sajrs.v32i1.54105 
Koçak, F. (2016). Türkiye'de bisiklet kullanımı: Bisiklet kullanma nedenleri ve elde edilen faydalar. Journal of Human Sciences, 13(3), 5760-5771. doi:10.14687/ihs.v13i3.4190

Titze, S., Stronegger, W., Janschitz, S., \& Oja, P. (2007). Environmental, social, and personal correlates of cycling for transportation in a student population. Journal of Physical Activity \& Health, 4(1), 66-79.

Titze, S., Stronegger, W. J., Janschitz, S., \& Oja, P. (2008). Association of built-environment, socialenvironment and personal factors with bicycling as a mode of transportation among Austrian city dwellers. Preventive Medicine, 47(3), 252-259. View Article: DOI: http://dx.doi.org/10.1016/j.ypmed.2008.02.019

\section{Extended English Abstract}

The aim of this study is to reveal the reasons of bicycle use for cyclist in Turkey and the benefits of cycling. Knowing individuals' reasons for cycling is important for dissemination policies regarding the use of bicycles. There are many reasons for bicycle use today. There are many different reasons for bicycle use such as traveling, racing, mountain biking, public service, and commute biking (Daley \& Rissel, 2011). Regular use of bicycle reduces air pollution and heavy traffic while boosting health and wellbeing of the individual (Daley \& Rissel, 2011). It has been found that using bicycle for commuting improves physical performance and health for men and women (Engbers \& Hendriksen, 2010). As a transportation or leisure time activity, bicycle use has environmental, personal, or social aspects such as personal satisfaction, sense of security, and social support (Hendriksen et al., 2000). O'Connor \& Brown (2007) has stated that bicycle use has positive effect on social interaction. On the other hand, some researchers treat bicycle use as a serious leisure activity (O'Connor \& Brown, 2007; Brown et al., 2009). Serious leisure is the systematic pursuit of an amateur, hobbyist, or volunteer core activity that is highly substantial, interesting, and fulfilling and where, in the typical case, participants find a (leisure) career in acquiring and expressing a combination of its special skills, knowledge, and experience (Stebbins, 2007). Cycling as a serious leisure is considered as a less organized, unstructured type of sports that informally involves weekly group trainings and participating in competitions (O'Connor \& Brown, 2007). Ho et al., (2015) have stated that increased interest in environmental protection and sustainable development can increase bicycle use. In his study, Horton (2006) also states that bicycle use in the UK is an important factor in creating a society with a green vision regarding sustainability. Researchers has benefited from many sociological approaches to explain the factors that motivate individuals to cycle. Ho et al., (2015) have suggested that people use bicycles to achieve fundamental values such as happiness, belonging, self-esteem, and self-realization. Based on Maslow's five dimensional Hierarchy of Needs it has been explained that leisure/recreational cyclists do this activity to fulfill personal needs on the self-realization level (Ho et al., 2015).

Research is based on the screening model.110 women (Mage $=30.46 ; \mathrm{SD}=8.78$ ) and 496 men (Mage $=30.47$; $\mathrm{SD}=10.12$ ) of 606 cyclists in total, who have been selected using convenience sampling, participated in this study voluntarily. In addition to the personal information form, twosection questionnaire prepared by the researcher has been used. In the personal information form there are 9 questions to obtain some personal information considered to contribute to research; in the second section there are 17 items to determine the reasons for bicycle use; and in the third section there are 18 items to demonstrate the benefits of bicycle use.17 items on the second section and 18 items on the third section of data collection tool has been scored based on 5-point Likerttype assessment method as follows: "agree" $=3$ points (2,34-3.00), "moderately agree" $=2$ points $(1,67-2,33)$, "disagree" $=1$ points $(1,00-1,66)$. In the study, individual characteristics of cyclists have been provided alongside frequency and percentage distribution. Also, in order to demonstrate participants' reasons to cycle and the benefits they receive as a result, mean and standard deviation, frequency and percentage distribution has been calculated. To compare participants' views on 
reasons for bicycle use and its benefits according to their individual characteristics Chi Square Test. In the study, the reliability analysis Cronbach's Alpha has been determined by internal consistency coefficient. Thus, Cronbach's Alpha internal consistency coefficient has been calculated as .875 for participants' reasons for bicycle use, and .842 for the benefits they get as a result of bicycle use. According to the relevant literature (Nunnally \& Bernstein, 1994) these values show that the data collection tool is reliable. The margin of error in the study has been determined as 0.05 .

In the section regarding participants' reasons for bicycle use, the first three items they mostly agreed on are "I like cycling" and "To protect my wellbeing." In the same section, the first three items they mostly disagreed on are "Not to be lonely," "Influence of those around me," and "To join a group of friends easily." In the section regarding the benefits of bicycle use, the first three items they mostly agreed on are "I feel more strong and healthy," "I feel happier," and "I relieve stress." In the same section, the first three items they mostly disagreed on are "I get new business contacts," "My social status increases," and "I express myself more easily." As a result, the higher the income and education level get, the less people participate cycling. Also, it has been observed that single people have more positive attitude towards cycling compared to married people. In addition to this, gender, working status and duration have no effect on individuals' participate cycling. 